\section{UAB}

Universitat Autònoma de Barcelona

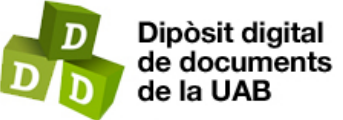

de la UAB

This is the accepted version of the article:

Padilla, Emilio. «Climate change, economic analysis and sustainable development». Environmental Values, Vol. 13 (2004), p. 523-544. DOI $10.3197 / 0963271042772622$

This version is available at https://ddd.uab.cat/record/247640

under the terms of the Areeess

license 
This is the postprint version of the article:

Padilla, E. (2004) "Climate Change, Economic Analysis and Sustainable Development", Environmental Values, Vol. 13, n. 4, pp. 523-544.

https://doi.org/10.3197/0963271042772622

\title{
Climate Change, Economic Analysis and Sustainable Development
}

\author{
Emilio Padilla
}

Department of Applied Economics

Universitat Autònoma de Barcelona.

Edifici B, Campus de Bellaterra,

08193 Bellaterra

Spain

Tel: 34935813415

Fax: 34925812292

E-mail: Emilio.padilla@uab.es 


\title{
Limitations, omissions and value judgments of conventional economic analysis of climate change. Towards an analysis consistent with sustainable development
}

\begin{abstract}
This paper discusses the limitations, omissions and value judgments of the application of conventional economic analysis in the evaluation of climate change mitigation policies. It is argued that these have biased the result of the assessment models towards the recommendation of less aggressive mitigation strategies. Consequently, this paper questions whether they provide appropriate policy recommendations. The unequal distribution of rights implicitly assumed in conventional economic analyses applied to climate change is questioned and an alternative approach considering a distribution of rights consistent with sustainable development is put forward. Finally, the points that an analysis consistent with sustainable development should take into account are presented.
\end{abstract}

Key words: climate change, emissions control, evaluation of policies, future generations, institutional innovations, sustainable development 


\section{Introduction}

The warming of the Earth has generated an environmental concern without precedent, which is reflected in the number of international conferences organized to discuss it. The most visible result has been the commitment to reduce emissions set down by the Kyoto Protocol in 1997 and the agreement to make it operative in Bonn 2001. However, in spite of the notable softening of the terms agreed to in Kyoto, the final agreement was not ratified by the main country responsible for the problem. The greater instability in climatic events and the natural disasters experienced in the last decade, such as hurricane Mitch in 1998 and the floods of Venezuela in 1999 and of Germany in 2002, together with the increasing scientific knowledge about the phenomenon, have increased this concern. However, the results of conventional economic analyses applied to climate change do not seem to justify this concern and have been used rather to legitimatise and give a "scientific" justification to the noregulation policy and the free performance of the energy sector. This paper discusses the limitations, omissions and value judgments of the analyses that have led to this result and examines the points that should be considered in the analysis of climate change policies in order to be consistent with a sustainable development requirement.

The paper is organized as follows. Section 2 briefly explains the uncertainties of the greenhouse effect, its consequences for climate, and the potential impacts of climate change. Section 3 studies the problems of the application of conventional economic analysis to climate change and Section 4 studies some other biases that have been introduced in the study of climate change mitigation policies. Section 5 highlights the points to be considered for an analysis consistent with sustainable development. Section 6 presents the conclusions.

\section{Greenhouse effect and climate change}

Global warming and the resulting climate change are due to the intensification of what has been termed "the greenhouse effect", which is a natural phenomenon, caused by various gases present in the atmosphere, and it is responsible for the temperatures that make the Earth inhabitable. The 
problem arises because human activity has accelerated the accumulation of these gases, mainly through the combustion of fossil fuels, which has originated the warming process. According to the Intergovernmental Panel on Climate Change (IPCC) (2001a) between 1750 and $2000 \mathrm{CO}_{2}$ emissions have contributed $60 \%, \mathrm{CH}_{4} 19.8 \%$, $\mathrm{CFCs} 14 \%$, and $\mathrm{N}_{2} \mathrm{O} 6.2 \%$, measured in terms of radiative forcing. $\mathrm{CO}_{2}$ concentrations have increased $31 \%$ between 1750 and 2000, from 280 to 366.8 ppm, and IPCC (2000) emission scenarios foresee a concentration between 490 and $1200 \mathrm{ppm}$ by the end of this century, which would severely alter global climate.

One particularity of climate change is that the consequences for each country do not depend on its individual contribution, but rather on the global deterioration. Another characteristic is that its effects are long lasting, if not irreversible. Lastly, the impacts of the alterations are hard to determine since the processes are so complex. Because of these characteristics, together with the free access to an environment shared by all present and future individuals, the necessary incentives for a sustainable administration are not given. Usually this problem is identified with "the tragedy of the commons", explicitly stated by Hardin (1968). However, common management of public goods works appropriately in many cases, therefore, the problem is rather one of "free access", where there is no management limiting the use of the resource (Aguilera-Klink 1994; Pearce 1999). In short, we are dealing with an externality problem of uncertain magnitude, which affects a public good at global scale and at both at intra- and intergenerational levels.

\subsection{Uncertainties associated with climate change}

There is uncertainty and ignorance about basic questions of climate change. First, there is the difficulty of measuring emissions, and of making predictions about future concentrations. Second, there are many interactions that complicate the study of the relation between emissions concentration and warming —-some greenhouse gases produce chemical interactions (causing problems such as the ozone layer depletion or acid rain) and their final effect on global warming is more difficult to determine than in the case of $\mathrm{CO}_{2}$. Third, even assuming a certain mean level of warming, there is uncertainty about the climatic impact on the different regions of the world. Fourth, there is the difficulty of identifying and estimating the magnitude of the impacts that climate change might cause 
on the environment and on human well-being. Lastly, uncertainty persists when considering what sacrifice (in monetary terms) a stricter control of emissions would imply. In each one of these stages the collaboration of specialists of different fields becomes necessary.

\subsection{Global warming and climate change}

According to the Intergovernmental Panel on Climate Change last full report (Third Assessment Report, IPCC 2001a), the average temperature of the earth's surface has increased around $0.6^{\circ} \mathrm{C}$ since 1861 . It is estimated that the increase in the last 10000 years has been $1{ }^{\circ} \mathrm{C}$, the rate of warming being constant until the last decades of the $\mathrm{XX}$ century, in which it increased to $0.15^{\circ} \mathrm{C}$ per decade. The IPCC estimates that the average temperature could increase between 1.4 and $5.8^{\circ} \mathrm{C}$ between 1990 and the end of XXI century, which is expected to cause a rise in sea level by 0.09 to 0.88 metres during the same period. This is a rate of warming without precedent in human history.

However, the greatest problem of global warming is not the average increase in temperature, but the associated climatic anomalies and changes that might occur. The result of global warming can be more heat or more cold, more rains or more droughts, depending on the region and, in general, more climatic instability with an increase in the frequency of natural disasters such as cyclones, droughts or floods. Furthermore, the relationship between average warming and climate change is complex. The increase in average Earth surface temperature might be a useful indicator of the severity of the problem, since the greater the warming the more the climate alterations. Nevertheless, the global damage is not a simple linear function of the temperature increase.

\subsection{Climate change impacts}

Some of the foreseeable impacts of the aforementioned climatic changes are agriculture losses, losses in biodiversity and forests, sea level rise, disease, energy costs, migration costs, natural disasters, losses in recreational activities, and water supply problems. However, if warming is mild the impacts might be positive for some regions: e.g. increase in water availability, better crops and warmer winters. Several models of integrated assessment have been made in order to incorporate the interrelations between climate and economy (a review can be found in Rotmans et al. 1998). These 
models present estimations, in monetary terms, of the effects caused by global climate change and emission reduction policies. On the whole, it is calculated that global GDP would change little with small temperature increases while greater temperature increases would boost the net losses (IPCC 2001b). The impacts would be much greater in poor countries, due partly to their lower capacity to adapt and their greater vulnerability; in some cases, the local impact could be catastrophic. However, the impact difference in different areas brings about serious problems in the search for solutions as those countries which are less affected have few incentives to participate in an agreement implying costs.

According to the IPCC there is the possibility of extreme impacts, like changes in ocean currents, a considerable melting of polar ice-caps, and an accelerated warming due to the release of carbon and methane pockets or to carbon cycle feedbacks in the terrestrial biosphere, among others. Should they occur, their effects would be catastrophic, and possibly irreversible in the long term. Although it is unknown, we can speculate that the probability of these phenomena depends on the rate, magnitude, and duration of climate change (IPCC 2001b). However, this possibility is simply ignored or assigned an arbitrarily low probability in most models' calculations. What is certain is that, the more extreme the events, the more difficult humans will find it to adapt.

According to most conventional calculations, one would need to sacrifice around $2 \%$ of the global annual GDP to make a significant difference in the control of emissions. As Schelling (1992: 8) affirms, it only "postpones the GDP of 2050 to 2051", which might be considered a trivial impact on GDP. The IPCC (2001c) estimates the total cost of stabilizing atmospheric $\mathrm{CO}_{2}$ concentrations at 450 , 550 and $650 \mathrm{ppm}$ to lie in the range $2.5-18,1-8$ and $0.5-2$ trillions of 1990 US\$, respectively (discounted to 1990 at 5\%). Many economists have used these numbers to argue that emissions control can threaten economic development. However, given that most models assume a global absolute income increase by $2-3 \%$ per year (with greater growth in poorer countries), this means that "the cost of 'climate insurance' amounts to 'only' a couple of years delay in achieving very impressive growth in per capita income levels" (Azar and Schneider 2002: 77), even when this cost is as high as 5\% of global income per year. Thus, even for the most pessimistic models, concentration stabilization and a great increase in global income are compatible. Moreover, "the difference in annual average growth 
rates between a case with an unconstrained use of fossil fuels and a case with strong restrictions on the use of fossil fuels would likely be less than a tenth of a percent per year over this century" (Azar and Schneider 2002: 78). Nevertheless, in general, current conventional models suggest that it is not profitable to take action for mitigating climate change, or that the action should be very limited (e.g. Manne and Richels 1992, 1999; Peck and Teisberg 1992, 1994, 1999; Nordhaus 1993, 1994; Manne, et al. 1995; Nordhaus and Yang 1996; Chakravorty et al. 1997; Nordhaus and Boyer 1999; Hamaide and Boland 2000), a result that has strongly influenced the energy policy of some industrialized countries. However, the validity of this policy recommendation is challenged by the limitations, value judgments and biases in critical assumptions that many of these models incorporate.

\section{Problems of conventional economic analysis applied to climate change}

Many of the models that have been used are based on conventional economic cost-benefit analysis (e.g. Nordhaus et al. various years; Peck and Teisberg 1992; Manne et al. 1995). On the other hand, various models have also been created to search for cost-effective paths to reduce emissions and achieve specific emissions or atmospheric concentrations goals. These models, in spite of not being as pretentious, maintain a good part of the limitations of the conventional economic cost-benefit analyses applied to climate change and most of them also incorporate some biases in assumptions that are critical for their results, which limits their capacity to give appropriate policy recommendations.

\subsection{The discounting of climate change impacts}

Conventional economic analysis gives less importance to flows that take place in the future (a thorough review of the problems of conventional discounting can be found in Broome (1992) and Price (1993, 1996)). The application of conventional discounting devalues and practically removes from the analysis the impacts that occur in the distant future in such a way that for these models the maintenance of the necessary conditions for life far in the future is of negligible present value (although this would not be the case if these conditions were given an indefinite value). Part of the controversy about the models applied to climate change has focused on the choice of the discount rate. 
Broome (1992), Cline (1992), Nordhaus (1994), and Fankhauser (1994) agree about the importance of this choice for the prescribed mitigation level of greenhouse gases. Usually, the social discount rate (s) in these models is expressed with the Ramsey formula:

$$
\mathrm{s}=\rho+\eta \mathrm{g}
$$

where $\rho$ is the pure time preference rate, $\eta$ is the elasticity of marginal utility (absolute value) of consumption and $\mathrm{g}$ is the growth rate of per capita consumption. That is to say, discounting is applied because of impatience and the belief that in the future there would be more wealth per head.

Conventional economic analysis applies the time discount of present society to discount all costs and benefits that will occur in the future, as if all future impacts occurred to present individuals. The consumption of future individuals is discounted with a rate that shows the impatience of present society, while the logical procedure would be to consider the preferences of present society regarding the well-being of the future generations suffering climate change impacts. An intergenerational weighting appropriately showing these preferences should be applied. However, considering these altruistic preferences does not guarantee that the interests of future generations are appropriately taken into account. If future generations have certain rights that should be respected, these rights should be included in the analysis (Padilla 2002), a point developed in section 5.

The practical application of the argument of the decreasing marginal utility of consumption is also controversial. To apply a high discount rate because of an assumed future prosperity could lead to compromising this very prosperity because of undervaluing the impacts of future climate change. Moreover, many of the models applied to climate change extrapolate future rates of economic growth from past behaviour, without considering the negative impacts that this growth has caused on the environment.

Furthermore, if discounting is applied to future individuals because of the belief they will be richer, this same reasoning would justify weighting the impacts of present individuals according to their wealth, which is rarely done (Azar and Sterner 1996). Conventional models assume that future individuals will be richer. This induces the idea that it is not profitable to make efforts in the present to reduce emissions that will affect future people (with a much smaller marginal utility). According to Schelling (1995), if in the future everybody is better off, the greater marginal utility would be the one 
of present poor people and it would be more efficient to increase their standard of life. Neumayer (1999) argues that a lower time discounting would be inconsistent with intergenerational equity, since he believes that the future will always be richer. However, it should be taken into account that the countries that are creating most of the problem are rich countries, while the ones that will suffer most severely are poor countries. Actually, climate change is already affecting poor countries with an increasing frequency of anomalies and climatic disasters. It is, at least, doubtful that the poor of the future will be in much better condition than the rich of the present; even more so if devastating effects of climate change on their ecological and socio-economic systems are allowed. If the argument of marginal utility is used coherently, then when comparing costs and benefits, it should be taken into account that the hypothetical renouncement of greater growth that might be involved in a stricter emissions control would be at the expense of the richest countries (main emitters), while climate change mitigation would entail that the standards of life in the poor countries (with a much higher marginal utility) do not deteriorate. According to their higher marginal utility, the poor should be given greater weight than they are given in conventional economic cost-benefit analyses. Social costbenefit analysis is based on a weighting according to individual's wealth (see Squire and van der Tak, 1975), however, it is little advocated by mainstreamers.

Many economists still use a much cruder basis for discounting, that is, the opportunity cost of investment funds. In this way the resources would be placed in the highest yielding projects, so obtaining a greater future well-being. This argument is hardly justifiable in the intergenerational context as it is based on the full reinvestment of the revenues obtained with the exploitation of the resources, which has not occurred in the past and is unlikely to occur in the future (Price, 1996).

\subsection{The Hicks-Kaldor compensation criterion and valuation problems}

Conventional economic cost-benefit analysis is based on the Hicks-Kaldor compensation criterion. According to this, a project is socially profitable if those that gain could compensate those that lose (Kaldor criterion), or if the losers cannot pay the winners not to undertake the project (Hicks criterion). If the present value of the benefits is greater than the present value of the costs, then it is assumed that those who benefit from the project can compensate those that are harmed by it, 
improving their initial situation (potential Pareto-improvement). If compensation was paid, everybody would gain and a net gain for society would occur (actual Pareto-improvement). However, whether this compensation occurs is considered irrelevant for the result of economic cost-benefit analysis. In ordinary evaluations, economic cost-benefit analysis without compensation can be justified if it is assumed that the marginal utility of a monetary unit of costs has the same social value as a monetary unit of benefits (Lind, 1997). Another justification is that, if there are many small projects everybody gains on the average (thus, compensation would not be in the scope of the project, but in the political sphere). As Lind states, the ethical validity of the first argument depends on the initial distribution being judged as correct. In climate change, the very unequal distribution (both of impacts and incomes) between those that gain and those that lose would invalidate this justification, while the magnitude of the impacts we are considering would invalidate the second one. Therefore, cost-benefit analysis of projects without compensation would not be appropriate in the context of climate change. Furthermore, currently, there are no institutions in place to make sure that a monetary compensation between present and future generations will find its way into the hands of people meriting compensation, so nothing indicates that the compensation from those that "win" to those that "lose" needed for a Pareto-improvement would be implemented.

Another issue is whether monetary compensation is appropriate. Accepting that a monetary compensation is valid requires making very strong assumptions, such as substitutability between any types of goods, which is not scientifically based, but rather based in faith or in the interest of having easily tractable models. Climate change might cause irreversibilities and catastrophes, and some goods and processes that cannot be replaced can be destroyed. There are also many relevant factors that are at least questionable that could be translated into the monetary valuations of real or hypothetical markets. Furthermore, it implies a strong value-laden premise to assume that doing harm can be compensated by doing some other good, or that doing some good entitles us to deliberately do harm to other people (without their consent). Many authors argue that ecological damage to future generations cannot be compensated by doing them some other good (Sen 1982; Spash 1994; Azar 2000). In decisions affecting elemental rights, such as the basic conditions of life of future generations, the compensation criterion might not be acceptable. 
Conventional cost-benefit analyses applied to climate change assume that values are known, exogenously determined and translatable into money terms. Although people do not have well articulated values about ecosystems, analysts assume that they do (and that they can be applied in other places and periods), and that the monetary values assumed in the studies determine the preferred policies (Lave and Dowlatabadi 1993). The values of ecosystems have more dimensions than those translatable into monetary terms, and these different dimensions should be taken into account and not just ignored, imposing the particular view of those that consider that everything should be reduced to money terms (Funtowicz and Ravetz 1994). Different regions, populations, and cultures, as well as different generations, are affected in different ways by climate change, and in some cases they value the same goods in a different way (Lave and Dowlatabadi 1993). The compensation criterion also implies pricing human lives, which, in itself, requires the assumption that the method for determining its value is correct and that money in rich countries can be compared with lives in poor countries (Azar 2000), which again implies a determinant value judgement —one of the issues that generated more controversy in climate change debate was the use by the IPCC (Pearce et al. 1996) of a monetary value assigned for a death in a rich country 15 times higher than for a death in a poor country, values based on the estimates by Fankhauser (1995) and Tol (1995) derived from willingness-to-pay measures. Another problem of the valuations included in economic cost-benefit analyses is that the willingness-to-pay measure is often used instead of the willingness-to-accept measure (e.g. Fankhauser 1994, 1995; Tol 1995; Pearce et al. 1996). There is important empirical evidence that counters neoclassical theory, showing these valuations to be very different, even in the case of small income effects (where the impact is small in relation to the total income of the individual). In contingent valuation studies, the ratio between willingness-to-accept and willingness-to-pay ranges from 2 to more than 10. In the case of climate change, the income effect is significant, which causes the willingness-to-pay to be much smaller than the value of the compensation people would accept. In addition to the income effect, there is the endowment effect (Kahneman and Tversky 1979), which implies than losses are more weighted than gains. The difference between willingness-to-pay and willingness-to-accept can also be due to the consideration of some goods as inalienable. These explanations, and the empirical evidence that supports them, indicate that it is incorrect to use one 
measure when it is not the one stated by the problem, and even less so in a problem with the great magnitudes of climate change.

\subsection{The distribution of rights in conventional economic analysis}

Conventional economic cost-benefit analyses applied to climate change implicitly assume that the Earth and all its resources, including the climatic system, belong to the present, and that it has the right to do with them whatever cost-benefit analysis's criterion shows as acceptable-including the right to destroy them. Then, for these models there is a natural right to pollute, without obligation to compensate those that suffer the consequences of this pollution. The only valid valuations for economic cost-benefit analyses are those of markets, where future generations cannot bid and presentday poor people have very limited means of doing so. However, considering that the same existence of future generations should depend only on the present preferences that can be expressed in real or hypothetical markets seems, at least, ethically questionable.

Starting from the conventional perspective, Hamaide and Boland (2000) try to "overcome" the limitation of Hicks-Kaldor potential compensation criterion by studying "Pareto-optimal" solutions where "everybody wins" thanks to effective compensation, which they call the "cooperative solution". Their solution suggests that poor countries, the most benefited by mitigation policies, pay an economic compensation to China and the United States so that they control their emissions. In spite of the neutrality that conventional analysis tries to convey, it is undeniable that it is laden with strong value judgements that are ethically questionable and politically unacceptable — it is hardly justifiable on ethical grounds that poor countries should subsidize the United States's emissions control.

The potential compensation implicit in optimisation analyses consists of the hypothetical payment by those that will be affected in the future in order that the present incurs the "costs" of controlling its emissions. The optimal level of mitigation is achieved when the so-called "marginal cost" of reducing emissions equals the present discounted value of the "marginal benefit" experienced by future generations. If effective compensation was required it would involve the payment of a compensation by future generations in order to avoid the present destroying the necessary conditions for life in the future. Moreover, this compensation would be from poor to rich countries. An 
intergenerational compensation like this would be very difficult to establish, but the main point is that it results from the assumption of a very unfair distribution of rights.

The countries that are most affected by climate change are, with all probability, the poor ones, while the main responsible for the problem and the only ones that have resources to act fall to the rich countries (see Tóth (1999) for a review on the issues of equity in climate change). These countries have an ecological debt to the rest of the world and to future generations, since they have appropriated and made an unsustainable use of an environment that belongs to all present and future individuals (for an analysis on the "ecological debt" see Martínez Alier (1998)). It is not justifiable, under any acceptable concept of equity or justice, that the poor have to suffer the ecological burden that involves the greater development of rich countries.

Moreover, stating the problem as costs for the present and benefits for the future tends to facilitate the approval of policies unfavourable to the future, since usually, a phenomenon is more weighed when it is considered as a loss than when it is considered as a gain (Kahneman and Tversky 1979). This can also affect the chosen discount rate. As Mohr (1995) states, the ambiguity of the time preference depending on whether it refers to costs or benefits, implies that according to how the problem is presented, the citizens can be persuaded to agree with a particular opinion. Unfortunately, the result of this persuasion is often presented as the only "scientific" result.

There are strong arguments for questioning the ethical validity of the distribution of rights of conventional analysis and the application of the (hypothetical) compensation criterion to climate change. It also seems clear that in order to achieve a more transparent analysis the more than questionable value judgements that are hidden behind the analyses should be made explicit.

\section{Some additional limitations, omissions and value judgments}

The problems of the models used for determining the appropriate mitigation policies go beyond the limitations of conventional economic cost-benefit analysis. In general, both cost-benefit and cost-effectiveness analyses applied to climate change have incorporated value judgements, 
omissions, and assumptions about factors that critically affect their results. The problem is that the biases they introduce always lean in the same direction: they tend to undervalue the losses and overvalue the economic gains of climate change, and hence lead to the recommendation that either emission control should be mild, or that there should be no control, at least in the short term.

First, they tend to make quite optimistic assumptions about the virtues of economic growth. Current models usually assume high rates of future economic growth justifying it by past growth, without taking into account the negative environmental effect of this growth. This leads to the application of a high discount rate (because of decreasing marginal utility of consumption) and to assuming a great capacity of adaptation, thus considering less serious the impacts caused by climate change.

Another bias of some of the most influential models is highlighted by Price (1995) who states that Nordhaus (1993) may seriously underestimate the residence time and costs of atmospheric $\mathrm{CO}_{2}$. Price argues that the parameters estimated in Nordhaus's model of $\mathrm{CO}_{2}$ uptake are wrong as land use sources and "missing sinks" are not adequately considered, and oceanic uptake is modelled as a simple exponential. Schultz and Kasting (1997) argue that many of the integrated assessment climateeconomy models are based on pre-industrial $\mathrm{CO}_{2}$ uptake rates. These undervalue the life of $\mathrm{CO}_{2}$ in the atmosphere as they do not appropriately consider the reduced rate of uptake as atmospheric and oceanic partial pressures converge. Consequently, the future concentrations of $\mathrm{CO}_{2}$ in the atmosphere and the persistence of global warming are underestimated by Nordhaus $(1993,1994)$, which biases the result towards lesser "optimal” reduction.

The climatic models employed in the studies are continuous and do not reflect the discontinuities that might occur. They assume that the change in $\mathrm{CO}_{2}$ atmospheric concentrations is smooth and marginal (which could be reasonable) and then "deduce" that climate change and their impacts will be smooth and marginal (Pizer 1996). This involves ignoring issues such as that oceanic currents and the atmospheric system could change to an alternative equilibrium causing rapid and extreme changes, with catastrophic impacts in some cases. Moreover, estimates generally do not take into account the effects of changes in the variability of climate (IPCC 2001b). Conventional evaluations (e.g. Nordhaus' studies) also ignore to a great extent the negative effects of global 
warming on ecosystems (Howarth 1996).

Under certain conditions (risks exogenously determined, and certainty about the different possible results and their respective probabilities) conventional methods can lead to an efficient allocation of resources in the presence of risk. These conditions are not met in the case of climate change, where the risks are poorly understood and depend on human performance. The models have tended to assume that uncertainty is small and manageable (Weyant et al. 1995). However, in climate change many interactions occur between complex natural and social systems in which little is known. Not recognizing the levels of uncertainty and ignorance in the models leads to erroneous results that should not be qualified as "optimal". Moreover, these models ignore the possibility of extreme phenomena and catastrophic events, or simply assign them a negligible probability, when in fact both the possible results and their corresponding probabilities are unknown. A factor that should be important in decision-making is not taken into account, which biases the result towards a lower emissions control. As Azar (1998) argues, almost any level of mitigation can be justified just by changing the probability assigned to these catastrophic events, and there is strong uncertainty about the true probability. While the information and models on which the assessments base their results are very uncertain and sensitive to value judgments, the authors tend to present too precise "scientific" estimations and are too self-confident in their policy recommendations in an unjustified way —or at least not justified on a scientific basis — a point already highlighted by Funtowicz and Ravetz (1994). Most analyses (including the ones by Nordhaus) overlook the fact that, besides its impact in greenhouse effect, emissions control has other significant associated positive effects (secondary benefits). The reduction in the particles that result from the combustion of fossil fuels (such as $\mathrm{SO}_{\mathrm{x}}$, $\mathrm{NO}_{\mathrm{x}}$ and volatile organic compounds) would lead to a reduction in pollution and the resulting enhancement of health and well-being. If this were taken into account, the control of emissions as well as the rate of reduction would be greater than those indicated by most analyses (Ekins, 1996). Furthermore, the models rarely consider the possible positive economic effects associated with the control of emissions, such as the "double dividend" (environmental benefits and economic gains of reducing externalities with taxation, especially if distortionary taxes are reduced simultaneously) or the development of new sectors associated with mitigation technologies. 
Several studies (e.g. Nordhaus and Yang 1996; McKibbin et al. 1999; Nordhaus and Boyer 1999; Hamaide and Boland 2000) assume a negative or very low cost of reduction in poor countries and greater marginal costs of reduction in richer countries. The result is that, in order to achieve "global efficiency", the greater reduction should be made in poor countries. Chapman and Khanna (2000) argue that there is no clear theoretical or empirical basis for these assumptions. But, even if this was the case, focusing control efforts in the third world would not lead to a very ambitious environmental policy.

It is usually assumed that even if there were no controls, a peak in greenhouse gas emissions would occur, after which these emissions would diminish. This is known as the environmental Kuznets curve hypothesis, according to which the environmental problem would disappear in the long term thanks to economic growth. Empirical evidence for this hypothesis concerning greenhouse gases tends to refute it, especially in the case of $\mathrm{CO}_{2}$ (see e.g. Roca et al. 2001). Even if the hypothesis was true, the delinking between environmental pressure and economic growth would occur at very high levels of income and emissions, which are a very long way from current levels in the developing countries (Selden and Song 1994; Stern et al. 1996). Therefore, ambitious environmental policies should be applied if much higher levels of environmental degradation are to be avoided. Moreover, present forecasts of future emissions (IPCC 2000) are less optimistic than the ones used in these models.

Another point is that most models assume that technical change is exogenous. Important annual improvements in energy efficiency are assumed (reductions in the energy demand per unit of product) independent of the impact of energy prices, which translates into a continuous decline in energy intensity (the energy to real GDP ratio) over time. Chapman and Khanna (2000) argue that between 1980 and 1996 energy intensity has been constant at a global level, with a reduction in rich countries and an increase in poor countries. Therefore, past experience would not necessarily justify the application of such assumptions. On the other hand, the possibility of technical change induced by the response of firms to market conditions is, in general, not considered. There is evidence that an important part of technical change in the energy sector is endogenous (Grubb and Walker 1992). Grubb and Köhler (2000) analyse the consequences of assuming an important induced technical 
change and they conclude that it would involve the recommendation of accelerating emissions control because the same mitigation develops the knowledge that allows emissions control at lower cost and causes it to be very cheap in the long term.

Lastly, it should be pointed out that, for the moment, the impacts associated with the upper margin of warming estimated by the last report of the IPCC (2001b) have not yet been investigated. Consequently, the impacts of climate change and so the adequate reduction in emissions might have been underestimated.

\section{Towards an analysis consistent with sustainable development}

The most popular definition of sustainable development states that it is "...development that meets the needs of the present without compromising the ability of future generations to meet their own needs." (WCED 1987: 43). A development complying with this definition would not allow the present to use resources in a way that jeopardizes the opportunities of the future, so it implies an equity commitment with the future.

This equity commitment and a fair treatment to future generations would be guaranteed if the analysis recognized the rights of future generations to enjoy a global ecological and economic capacity non-diminished in relation to the one we presently enjoy and thus recognised the corresponding obligations of present generations (Padilla, 2002). In other words, recognizing that the Earth and its resources, including the climatic system, belong not only to the present rich people, but also to all (present and future) individuals. As Page (1983) states, life opportunities of future generations will be undiminished if they inherit the same resource base as present generations inherited. This view does not imply that present generations cannot take profit of natural resources, but that the global resource base should be maintained. There might be some goods susceptible of being compensated and others which cannot be substituted, such as basic processes and some critical levels of certain environmental goods, which should be protected.

Using this view, the biased position of conventional economic analyses of climate change would not be correct when they state the issue as the present incurring in some "costs" for reducing (or controlling) greenhouse gas emissions in order to yield some "benefits" for future generations. The 
issue is to deal with the limitation of uncontrolled emissions growth, recognizing the rights of future generations so that their ecological and socio-economic system does not deteriorate further in relation to the one we enjoy. This is not to "give" anything to future generations, but rather to stop taking away something to which, from the sustainable development perspective, they are entitled to.

Present generations have the responsibility to study how their performance will affect the climate and environment of future generations, and which is the least costly way of respecting their rights. From an ethical point of view this alternative distribution of rights would be a more legitimate starting point for the analysis of climate change policies.

The obligation to respect the rights of future generations that entails sustainable development, jointly with the limitations of conventional models, imposes an analysis of mitigation policies incorporating constraints in terms of climate change impacts. Given the impossibility of establishing an adequate compensation because of the uncertainties, ignorance, substitution problems, nonmarginal changes and the problems involved in the application of conventional discounting to climate change, the obligations of the present should lead to the "stabilization of greenhouse gas concentrations at a level that would prevent dangerous anthropogenic interference with the climate system", the ultimate objective of the United Nations Framework Convention on Climate Change. In this way, guaranteeing their ecological opportunities, a fair treatment to the future would be ensured. Moreover, the rights of the future should be respected in a way that involves the least sacrifice to the present.

Various papers have investigated cost-effective paths of reduction of emissions in order to achieve different concentration targets. Unfortunately, most of them have not been overly concerned with identifying what level of concentration is appropriate or consistent with sustainable development, neither have they worried about incorporating all the information that is relevant for decision-making, but have been undertaken as simple technical cost-minimization exercises. Some of the problems that these models embody have been shown above and many of them suggest an even smaller reduction of emissions in the short term than economic cost-benefit analyses (e.g. Richels and Edmonds 1995). Hammitt (1999) shows, for different concentration targets, a lower short-term aggressiveness in emissions control of these models. This has been explained by the following reasons: avoiding the 
premature retirement of existent capital stock; existence of carbon sinks, which means that the proportion of $\mathrm{CO}_{2}$ remaining in the atmosphere is lower for earlier emissions; technological progress, which causes cheaper emission reduction in the future; and because of discounting, which makes the present value of costs lower if reduction is delayed (Wigley et al. 1996). Nevertheless, these explanations are quite questionable. It has already been shown that if technical change is induced and not exogenous as is usually assumed, it is better to reduce emissions earlier (Grubb and Köhler 2000), and short term policies would accelerate the development of the changes that would reduce mitigation costs. Grubb (1997) casts doubts on the appropriateness of postponing the renewal of capital and argues that this could involve greater total costs, since it would also postpone the innovation which reduces mitigation costs. These results are also influenced by the fact that, in general, the impacts of different warming rates as well as the discontinuities and possible changes of equilibrium are not taken into account. If these factors were considered, one would question the appropriateness of prematurely reducing the rates of carbon uptake of natural sinks. In summary, a target- or objective-based approach does not necessarily involve a lower reduction than conventional cost-benefit analyses, especially if the objective has to be consistent with sustainable development.

One of the approaches that has gone further in the search for an integrated assessment coherent with sustainable development is the tolerable windows approach, a method explained and discussed in Petschel-Held et al. (1999), Yohe (1999) and Dowlatabadi (1999). Starting from the constraints on tolerable changes, it imposes limitations on the rate of warming, the level of concentrations, the path of emissions and finally the policy instruments. It can consider different types of information and does not require translating everything into monetary terms. Through this approach, the obligation of preserving the natural environment for future generations could become a quantitative constraint in policies.

Several authors argue that the targets approach is inconsistent with determining the optimal allocation of all resources. However, this criticism is based on the implicit premise of conventional analysis, that of not recognizing any rights of future generations. Even Nordhaus (1997), author of the most influential neoclassical optimisation model, sees a clear opposition between economic optimality and sustainable development and suggests the introduction of targets for the permissible levels of 
climate change.

Nevertheless, a serious limitation of cost-effectiveness analyses is that they do not take into account the short and medium term impacts, focusing only in the final long-term objective. This could delay the reduction of emissions, since higher short term emissions could be compensated with greater reductions in the long term, which does not happen in the cost-benefit approach (Grubb 1997). The short and long term sacrifices that the reduction involves are accounted for under both analyses, but the short and medium term consequences of emissions are only considered under cost-benefit analysis. This is inconsistent with the distribution of rights implied by our view of sustainable development.

An evaluation consistent with sustainable development requires, first, the introduction of limits to ensure that climate change impacts do not jeopardize the global ecological and economic capacity of future generations and, second, the consideration of all the different impacts that might occur. The impact of any climate change on the future implies an alteration of the endowment to be enjoyed by future generations and so should be considered in the determination of adequate policies. The structure of rights that sustainable development implies turns any impact that diminishes the capacity of the future into an obligation for the present. Once any intolerable (and so non-susceptible of being compensated for) impact is avoided, the compensation for any ecological debt acquired with the future for present contamination should be accounted for and made effective, and monetary compensation might not be the most appropriate kind. The necessary information for determining which impacts would be intolerable should be collected (a decision that cannot be based just on an economist's judgement or assumption but on trans-disciplinary research) and the institutional framework should be created to be able to establish and carry out the adequate compensations in order that the future can receive them (Padilla 2002).

\section{Concluding remarks}

This paper presented a critical review of the limitations, value judgments and omissions of the conventional evaluation models used in the problem of climate change. The first conclusion is that the 
implicit assumptions involved in the applications of conventional economic cost-benefit analysis to climate change are inappropriate for a problem with such an extreme uncertainty and severity for future generations. Moreover, all variables relevant for society should be taken into account, not only those that can be valued in money. It would be more reasonable to try to obtain solutions that could be considered satisfactory using all the available information (including the information that social costbenefit analysis might provide), and taking into account the interests of all stakeholders, than to attempt by conventional analysis to obtain "optimal" points at the margin through models based on unreal and strongly value-laden assumptions and that are unable to show all the facets of the problem. Most studies (including cost-effectiveness ones) have also tended to incorporate value judgements and arbitrary assumptions and even to ignore a large part of the relevant information, which has clearly biased the results towards the conclusion that climate change is not a problem requiring urgent action.

Conventional economic cost-benefit analyses applied to climate change implicitly assume that there is the natural right to pollute or even destroy the climatic system. The present paper rejects this premise and suggests an alternative approach in which future generations are entitled to a nondeteriorated ecological and economic capacity with respect to the one we enjoy, and therefore present generations have an obligation to avoid or to compensate for any further deterioration of it. An evaluation of mitigation policies starting from a distribution of rights consistent with sustainable development requires ensuring a habitable climate far in the future and establishing effective compensations for the negative impacts caused to the future. Many economists and politicians have argued that this would endanger economic prosperity, an assessment without any scientific basis as, in fact, even the most pessimistic analyses suggest that buying this "climate insurance" might be compatible with an impressive increase in economic wealth (Azar and Schneider 2002).

An appropriate assessment of the policies to apply in climate change also requires incorporating the growing knowledge about the phenomenon. In the evaluation of adequate policies, all relevant information should be taken into account without using model complexity to hide value judgements and arbitrary assumptions about questionable factors or hiding elements that are determinants for decision-making. On the contrary, the analysis should serve to clarify what are the trade-offs and the choices that can be made. Integrated assessment should be useful for improving the 
knowledge of the phenomenon through the same process. The gathering of information, the study of alternative policies, the estimation of impacts and the knowledge of the critical parameters should lead to a better position for making informed decisions.

Even if the models determining the adequate policies (consistent with sustainable development) are designed, it is necessary to ensure that there are institutions in place that can establish emissions control and can be responsible for the transfer of adequate compensations (for a review of the role institutions in environmental protection and of its appropriate design see Young (2002), Haas et al. (1993) and Esty (1994)). These institutions should be able to achieve reduction commitments by different countries according to their capacity and their responsibility in the problem. It is urgent that the adoption of international commitments should go beyond the Kyoto Protocol and the Bonn 2001 agreement. It is imperative that these institutions have the capacity to sanction atmosphere free-rider practices and so reduce the incentives to cheat on the agreements. The disappearance of credible sanctions (besides the wide consideration of natural carbon sinks) of the Bonn agreement calls its effectiveness into serious question.

Finally, people of poorer countries are suffering and will continue to suffer the most severe impacts of climate change, while some countries have occupied and are occupying much more environmental space in terms of historic $\mathrm{CO}_{2}$ emissions than would correspond to their population (Alcántara and Roca 1999). Rich countries have therefore a moral obligation to pay the "ecological debt" acquired in having expropriated and destroyed the right of poor countries to a non-deteriorated climate. From an ethical point of view, in the long term, the only justifiable distribution of rights is the one that gives the same right to any human being — present or future. The distribution according to current per capita emission, as established in the Kyoto Protocol agreements, strongly favours those that have contributed the most to the problem, which is clearly unfair.

\section{Acknowledgements}

I am grateful to Federico Aguilera Klink, Vicent Alcántara, Jeroen C.J.M. van den Bergh, Joan Martínez Alier, Giuseppe Munda, Joan Pasqual, Jesús Ramos, Jordi Roca, three anonymous reviewers, 
and the editor for their useful comments and suggestions on earlier drafts. The opinions expressed in this paper and any remaining errors are the sole responsibility of the author. Financial support from projects BEC2000-415 (Ministerio de Ciencia y Tecnología) and 2001SGR-160 (Direcció General de Recerca) is also acknowledged. 


\section{References}

Aguilera-Klink, F. 1994. "Some notes on the misuse of classic writings in economics on the subject of common property". Ecological Economics 9: 221-228.

Alcántara, V. and Roca, J. 1999. " $\mathrm{CO}_{2}$ emissions and the occupation of the 'environmental space'. An empirical exercise". Energy Policy 27: 505-508.

Azar, C. 1998. “Are optimal $\mathrm{CO}_{2}$ emissions really optimal?”. Environmental and Resource Economics 11: $301-315$.

Azar, C. 2000. "Economics and distribution in the greenhouse". Climatic Change 47: 233-238.

Azar, C. and Schneider, S.H. 2002. "Are the economic costs of stabilizing the atmosphere prohibitive?". Ecological Economics, 42: 73-80.

Azar, C. and Sterner, T. 1996. "Discounting and distributional considerations in the context of global warming”. Ecological Economics 19: 169-184.

Broome, J. 1992. Counting the Costs of Global Warming. Cambridge: White Horse Press.

Chakravorty, U., Roumasset, J. and Tse, K. 1997. "Endogenous substitution among energy resources and global warming”. Journal of Political Economy 105: 1201-1234.

Chapman, D. and Khanna, N. 2000. “Crying no wolf: why economists don't worry about climate change, and should". Climatic Change 47: 225-232.

Cline, W.R. 1992. The Economics of Global Warming. Washington DC: Institute for International Economics.

Dowlatabadi, H. 1999. "Climate change thresholds and guardrails for emissions". Climatic Change 41: 297-301.

Ekins, P. 1996. "The secondary benefits of $\mathrm{CO}_{2}$ abatement: how much emission reduction do they justify?”. Ecological Economics 16: 13-24.

Esty, D.C. 1994. Greening the GATT: Trade, Environment, and the Future. Washington D.C.: Institute for International Economics. 
Fankhauser, S. 1994. "The social costs of greenhouse emissions: An expected value approach". Energy Journal 15: 157-184.

Fankhauser, S. 1995. Valuing climate change: the economics of the greenhouse. London: Earthscan.

Funtowicz, S.O. and Ravetz, J.R. 1994. "The worth of a songbird: ecological economics as a postnormal science". Ecological Economics 10: 197-207.

Grubb, M. 1997. "Technologies, energy systems and the timing of $\mathrm{CO}_{2}$ emissions abatement. An overview of economic issues". Energy Policy 25: 159-172.

Grubb, M. and Köhler, J. 2000. "Induced technical change: Evidence and implications for energyenvironmental modeling and policy”. Working Paper 0031, Department of Applied Economics, Cambridge University.

Grubb, M. and Walker, J. 1992. Emerging Energy Technologies: Impacts and Policy Implications. London: Royal Institute of International Affairs.

Haas, P.M., Keohane, R.O. and Levy, M.A. 1993. Institutions for the Earth. Sourthes of Effective International Environmental Protection. Cambridge, Massachusetts: The MIT Press.

Hamaide, B. and Boland, J.J. 2000. "Benefits, costs, and cooperation in greenhouse gas abatement". Climatic Change 47: 239-258.

Hammitt, J.K. 1999. "Evaluation endpoints and climate policy: atmospheric stabilization, benefit-cost analysis, and near-term greenhouse-gas emissions”. Climatic Change 41: 447-468.

Hardin, G. 1968. "The tragedy of the commons”. Science 162: 1243-1248.

Howarth, R.B. 1996. "Climate change and overlapping generations". Contemporary Economic Policy 14: $100-111$.

IPCC. 2000. Emissions Scenarios. Summary for Policy Makers. Special Report of IPCC Working Group III, in http://www.ipcc.ch

IPCC. 2001a. Climate Change 2001: The Scientific Basis. Contribution of Working Group I to the Third Assessment Report of the Intergovernmental Panel on Climate Change. Cambridge: Cambridge University Press. 
IPCC. 2001b. Climate Change 2001: Impacts, Adaptation and Vulnerability. Contribution of Working Group II to the Third Assessment Report of the Intergovernmental Panel on Climate Change. Cambridge: Cambridge University Press.

IPCC. 2001c. Climate Change 2001: Mitigation. Contribution of Working Group III to the Third Assessment Report of the Intergovernmental Panel on Climate Change. Cambridge: Cambridge University Press.

Kahneman, D. and Tversky, A. 1979. "Prospect theory: An analysis of decision under risk". Econometrica 47: 363-391.

Lave, L.B. and Dowlatabadi, H. 1993. "Climate change policy: the effects of personal beliefs and scientific uncertainty”. Environmental Science Technology 27: 1962-1972.

Lind, R.C. 1997. "Intertemporal equity, discounting, and economic efficiency in water policy evaluation". Climatic Change 37: 41-62.

Manne, A.S. and Richels, R.G. 1992. Buying Greenhouse Insurance: The Economic Costs of Carbon Dioxide Emission Limits. Cambridge MA: MIT Press.

Manne, A.S. and Richels, R.G. 1999. "The Kyoto protocol: A cost effective strategy for meeting environmental objectives?”. Energy Journal, Special Issue: The Costs of the Kyoto Protocol - A Multi-model Evaluation: 1-23.

Manne, A., Mendelsohn, R. and Richels, R. 1995. "MERGE - A model for evaluating regional and global effects of GHG reduction policies”. Energy Policy 23: 17-34.

Martínez-Alier, J. 1998. "Ecological debt—external debt”, in http://www.cosmovisiones.com/DeudaEcologica/.

McKibbin, W.J., Ross, M.T., Shackleton, R. and Wilcoxen, P.J. 1999. “Emissions trading, capital flows and the Kyoto protocol". Energy Journal. Special Issue: The Costs of the Kyoto Protocol - A Multi-Model Evaluation: 287-333.

Mohr, E. 1995. "Greenhouse policy persuasion: towards a positive theory of discounting the climate future". Ecological Economics 15: 235-245.

Neumayer, E. 1999. Weak versus Strong Sustainability. Exploring the Limits of Two Opposing Paradigms. Cheltenham: Edward Elgar. 
Nordhaus, W.D. 1993. "Rolling the "DICE": An optimal transition path for controlling greenhouse gases”. Resource and Energy Economics 5: 27-50.

Nordhaus, W.D. 1994. Managing the Global Commons: The Economics of Climate Change. Cambridge MA: MIT Press.

Nordhaus, W.D. 1997. "Discounting in economics and climate change". Climatic Change 37: 315328.

Nordhaus, W.D. and Boyer, J.G. 1999. Roll the DICE Again: Economic Models of Global Warming. Cambridge MA: Yale University, MIT Press.

Nordhaus, W.D. and Yang, Z. 1996. “A regional dynamic general-equilibrium model of alternative climate-change strategies". American Economic Review 86: 741-765.

Padilla, E. 2002. "Intergenerational equity and sustainability”. Ecological Economics 41: 69-83.

Pearce, D., 1999. "Economic analysis of global environmental issues: global warming, stratospheric ozone and biodiversity", in van den Bergh, J.C.J.M. (ed.) Handbook of Environmental and Resource Economics. Cheltenham: Edward Elgar.

Pearce, D., Cline, W.R., Achanta, A.N., Fankhauser, S., Pachauri, R.K., Tol, R.S.J. and Vellinga, P. 1996. The Social Costs of Climate Change: Damages and Benefits of Control. Report of the IPCC Working Group III. Cambridge: Cambridge University Press.

Peck, S.C. and Teisberg, T.J. 1992. "CETA: a model for carbon emissions trajectory assessment". Energy Journal 13: 55-77.

Peck, S.C. and Teisberg, T.J. 1994. "Optimal carbon emissions trajectories when damages depend on the rate or level of global warming". Climatic Change 28: 289-314.

Peck, S.C. and Teisberg, T.J. 1999. “ $\mathrm{CO}_{2}$ emissions control agreement: incentives for regional participation”. Energy Journal. Special Issue: The Costs of the Kyoto Protocol - A Multi-Model Evaluation: $367-390$.

Petschel-Held, G., Schellnhuber, H.-J., Bruckner, T., Tóth, F. and Hasselmann, K. 1999. “The tolerable windows approach: Theoretical and methodological foundations". Climatic Change 41: 303-331. 
Pizer, W.A. 1996. Optimal Choice of Instrument and Stringency under Uncertainty: Dynamic General Equilibrium Analysis of Climate Change Policy. Washington DC: Resources for the future.

Price, C. 1993. Time, Discounting and Value. Oxford: Blackwell.

Price, C. 1995. "Emissions, concentrations and disappearing $\mathrm{CO}_{2}$ ". Resource and Energy Economics 17: 87-97.

Price, C. 1996. "Discounting and project appraisal: from the bizarre to the ridiculous", in Kirkpatrick, C. and Weiss, J. Cost-Benefit Analysis and Project Appraisal in Developing Countries. Cheltenham: Edward Elgar.

Richels, R. and Edmonds, J. 1995. "The economics of stabilizing atmospheric $\mathrm{CO}_{2}$ concentrations". Energy Policy 23: 373-378.

Roca, J., Padilla, E, Farré, M. and Galletto, V. 2001. "Economic growth and atmospheric pollution in Spain: discussing the environmental Kuznets curve hypothesis". Ecological Economics 39: 85-99.

Rotmans, J., Dowlatabadi, H., Fialr, J.A. and Parson, E.A. 1998. "Integrated assessment of climate change: evaluation of methods and strategies", in Rayner, E. and Malone, E.L. (eds.) Human Choice and Climate Change. Chapter 10. Columbus: Battelle Press.

Schelling, T.C. 1992. "Some economics of global warming". American Economic Review 82: 1-14.

Schelling, T.C. 1995. “Intergenerational discounting”. Energy Policy 23: 395-401.

Schultz, P.A. and Kasting, J.F. 1997. "Optimal reductions in $\mathrm{CO}_{2}$ emissions”. Energy Policy 25: 491550.

Selden, T.M. and Song, D. 1994. "Environmental quality and development: Is there a Kuznets curve for air pollution estimates?". Journal of Environmental Economics and Management 27: 147-162.

Sen, A.K. 1982. "The choice of discount rates for social benefit-cost analysis", in Lind, R.C. (ed.) Discounting for Time and Risk in Energy Policy. Washington DC: Resources for the Future: 325352.

Spash, C.L. 1994. "Double $\mathrm{CO}_{2}$ and beyond: benefits, costs and compensation". Ecological Economics 10: 27-36. 
Squire, L. and van der Tak, H.G. 1975. Economic Appraisal of Projects. London: John Hopkins University Press.

Stern, D.I., Common, M.S. and Barbier, E.B. 1996. "Economic growth, trade and the environment: implications for the environmental Kuznets curve". World Development 24: 1151-1160.

Tóth, F.L. (ed.) 1999. Fair Weather? Equity Concerns in Climate Change. London: Earthscan Publications.

Tol, R.S.J. 1995. "The damage cost of climate change toward more comprehensive calculations". Environmental and Resource Economics 19: 67-90.

Weyant, J., Davidson, O., Dowlatabadi, H., Edmonds, J., Grubb, M., Parson, E. A., Richels, R., Rotmans, J., Shukla, P.R., Tol, R.S.J., Cline, W. and Fankhauser, S. 1995. "Integrated assessments of climate change: An overview and comparison of approaches and results", in IPCC Climate Change 1995: Economic and Social Dimensions of Climate Change. Cambridge: Cambridge University Press: 448.

Wigley, T.M.L., Richels, R. and Edmonds, J.A. 1996. "Economic and environmental choices in the stabilization of atmospheric $\mathrm{CO}_{2}$ emissions". Nature 379: 240-243.

World Commission on Environment and Development (WCED). 1987. Our Common Future. Oxford: Oxford University Press.

Yohe, G.H. 1999. "The tolerable windows approach: lessons and limitations". Climatic Change 41: 283-295.

Young, O.R. 2002. The Institutional Dimensions of Environmental Change: Fit, Interplay, and Scale. Cambridge and London: MIT Press. 